\title{
Voice quality and speaking rate in Icelandic rhetorical questions ${ }^{\ddagger}$
}

\author{
Nicole Dehé and Daniela Wochner \\ Universität Konstanz, Department of Linguistics, Fach 186, 78457 Konstanz, Germany \\ Emails for correspondence: nicole.dehe@uni-konstanz.de and daniela.wochner@uni-konstanz.de
}

(Received 2 March 2021; accepted 17 January 2022)

\begin{abstract}
In this paper, we show that Icelandic uses the phonetic parameters of speaking rate, duration and voice quality (VQ) to distinguish between information-seeking questions (ISQs) and rhetorical questions (RQs). Specifically, durations are longer (speaking rate is slower) and nonmodal VQs are used more in RQs than in ISQs. Our findings for temporal parameters fit in with previous studies on the prosody of RQs in various languages. With respect to VQ, Icelandic differs, for example, from German and English in the location of breathy voice in the utterance (utterance-initial in German and English, utterance-final in Icelandic). We interpret the utterance-final position of breathiness in Icelandic RQs as a potential compensating strategy for the lack of phonological cues, i.e. boundary tones.
\end{abstract}

Keywords: duration; Icelandic; prosody; rhetorical questions; speaking rate; voice quality

\section{Introduction}

This paper deals with phonetic differences between information-seeking questions (ISQs) and rhetorical questions (RQs) in Icelandic, specifically voice quality (VQ) and speaking rate/global duration, focusing on polar and wh-questions. The prosody of the two illocution types (ISQs, RQs) has recently been compared for several languages, among them English (Dehé \& Braun 2020b), German (Braun et al. 2019), Standard Chinese (Zahner et al. 2021), French (Beyssade \& Delais-Roussarie, to appear), Estonian (Asu, Sahkai \& Lippus 2020), Italian (Sorianello 2018, 2019), Cantonese (Lo, Kiss \& Tulling 2019), Japanese (Miura \& Hara 1995) and Icelandic (Dehé, Braun \& Wochner 2018, Dehé \& Braun 2020a); see Dehé et al. (2022) for an overview. These studies show that speakers make use of the same prosodic parameters to indicate rhetorical meaning across languages: F0, constituent duration/speaking rate, and VQ. The ways in which they are used vary across languages, with most variation for f0 modification. Some of the

\footnotetext{
${ }^{\ddagger}$ The online version of this article has been updated since its original publication. A notice detailing the changes has been published at: https://doi.org/10.1017/S033258652200004X

(C) The Author(s), 2022. Published by Cambridge University Press on behalf of Nordic Association of Linguistics. This is an Open Access article, distributed under the terms of the Creative Commons Attribution licence (https://creativecommons. org/licenses/by/4.0/), which permits unrestricted re-use, distribution, and reproduction in any medium, provided the original work is properly cited.
} 
f0-related variation follows from prosodic typology (e.g. intonation languages vs. tone languages) and language-specific pitch accent inventories. Regarding VQ, non-modal VQ often signals rhetorical meaning. For example, breathy VQ occurs in sentence-initial position in German polar and wh-RQs (Braun et al. 2019) and English wh-RQs (Dehé \& Braun 2020b). In Chinese, glottal VQ occurs more frequently in RQs than in ISQs in both initial and final positions (Zahner et al. 2021). In German, VQ also distinguishes between questions and statements in general (e.g. more breathy voice in declarative questions than in declarative statements, Niebuhr et al. 2010). In several African languages, breathiness has been associated with questionhood (Rialland 2009 for utterance-final breathiness in polar questions in languages of the Gur family). Constituent durations are generally longer, or speaking rate slower, in RQs than in ISQs across languages. Faster speaking rate has also been observed in declarative questions than in string-identical statements (van Heuven \& van Zanten 2005 for Manado Maylay, Orkney English and Dutch, Niebuhr et al. 2010 for German). This is potentially relevant because RQs have been argued to be assertion-like (e.g. Han 2002), in that eventually, all discourse participants are committed to the propositional content of the utterance, and RQs are thus closer in meaning to statements than to questions.

For Icelandic specifically, Dehé \& Braun (2020a) show that ISQs and RQs differ in nuclear pitch accent types and in the type and frequency of prenuclear accents. The default boundary tone is low (L\%) across question and illocution types. Regarding duration, the first word of the utterance (finite verb in polar questions, wh-word in wh-questions) and the nuclear syllable (first syllable of object noun) are longer in RQs than in ISQs (Dehé et al. 2018). VQ and global durational parameters have not yet been included in the prosodic comparison of RQs and ISQs in Icelandic. The present paper addresses these research gaps, showing that Icelandic exploits both VQ and speaking rate/duration to distinguish between RQs and ISQs.

\section{Methodology}

The current study is a post hoc analysis of Dehé \& Braun's (2020a) data. While Dehé \& Braun (2020a) focus on the intonation of ISQs vs. RQs, the present paper investigates VQ and speaking rate/duration. The data was elicited in a production experiment mimicking dialogue situations; materials consisted of 21 pairs of polar and 21 pairs of $w h$-interrogatives (e.g. (1)). All wh-questions started with the $w h$-pronoun hver 'who'; the subject in all polar questions was einhver 'anybody'.

$\begin{array}{llll}\text { (1) a. Polar question: } & \begin{array}{l}\text { Borðar } \\ \text { eats } \\ \text { 'Does anybody eat limes?' }\end{array} & \begin{array}{l}\text { einhver límónur? } \\ \text { anybody }\end{array} & \text { limes } \\ \text { b. Wh-question: } & \begin{array}{l}\text { Hver } \\ \text { who } \\ \text { 'Who eats limes?' }\end{array} & \begin{array}{l}\text { borðar } \\ \text { eats }\end{array} & \text { límónur? } \\ & & & \end{array}$

Data of 17 native speakers of Icelandic were analysed (average age 26.9 years; age range 20-32 years; 11 female, six male). Overall, 645 target interrogatives were 
analysed, 313 polar (156 ISQs, 157 RQs) and 332 wh-questions (166 ISQs, 166 RQs), exactly the same utterances as in Dehé \& Braun (2020a). They were annotated in Praat (Boersma \& Weenink 2018). Following Braun et al. (2019), VQ was annotated on a perceptual basis, at four positions. VQ was annotated by the second author, with $7 \%$ of the data also annotated by a research assistant. Interrater reliability (Cohen's Kappa, Cohen 1960) showed substantial agreement $(90 \%, \kappa=0.71)$ (Landis \& Koch 1977). In wh-questions, the four positions were (i) the sentenceinitial $w h$-word (hver $/ \mathrm{k}^{\mathrm{h}} \mathrm{v}: \mathrm{r} /$ ), (ii) the initial, stressed syllable of the finite verb (e.g. /por/ in borðar /'por.ðar/ 'eats'), (iii) the initial, stressed syllable of the object noun (e.g. /li:/ in limónur /'li..mou.,nyr/ 'limes'), and (iv) the offset of the utterance (e.g. last syllable of límónur). In polar questions, the four positions were (i) the stressed syllable of the sentence-initial verb (e.g. /por/ in borðar), (ii) the initial, stressed syllable of the subject einhver (/ein/ in /'ein. $\mathrm{k}^{\mathrm{h}} \mathrm{v \varepsilon r} /$ 'anybody'), (iii) the stressed syllable of the object noun, and (iv) the offset of the sentence. Three types of VQ were perceptually classified: modal (neutral mode of phonation, Laver 1980), breathy (audible friction of the air) and glottalized (low frequency irregular vocal fold vibrations, Braun et al. 2021). ${ }^{1}$

Speaking rate was operationalized as the number of syllables per second. The actual sentence duration served as the frame of reference for the calculation, to which the number of assumed syllables for each target sentence was set in relation, i.e. any segmental reductions or deletions were disregarded. However, reductions were minimal given the short length of the utterances and the laboratory setting.

For statistical analysis, we used a series of linear mixed effects regression models (lmers) with illocution type (ISQ, RQ) and question type (wh, polar) as fixed factors and participants and items as crossed-random factors (random intercepts). Random slopes were added and retained if they improved the model fit (Bates et al. 2015, Matuschek et al. 2017), as indicated by the anova() function in R-studio (R Core Team 2013). For the analysis of VQ (categorical variable), we used generalized linear mixed models (glmers). For the analysis of a specific VQ, the relevant type of VQ was coded as 1 , the other two as 0 . The effect of the fixed factors was calculated for these modified dependent variables (Agresti 2002). Model fitting followed the same procedure as for lmers. $P$-values were calculated using the Satterthwaite approximation in the R package lmerTest and adjusted $\left(\mathrm{p}_{\mathrm{adj}}\right)$ by means of the BenjaminiHochberg correction (Benjamini \& Hochberg 1995).

\section{Results}

\subsection{Voice quality}

The results for VQ are plotted in Figure 1 (top: wh-questions; bottom: polar questions). In the first three positions, there were no interactions between illocution type and question type $(p>.5)$; we therefore report main effects. Breathy VQ occurred more often in RQs than in ISQs in all positions, but in the first three positions, observations for breathy VQ were too few to calculate statistical models.

We report the results for the four positions in turn. In sentence-initial position (verb in polar, wh-word in wh-questions), RQs were more often realized with glottalized VQ than ISQs, although the difference was not statistically significant $\left(p>.1, p_{a d j}=.4\right)$. There was a main effect of question type; polar questions were 


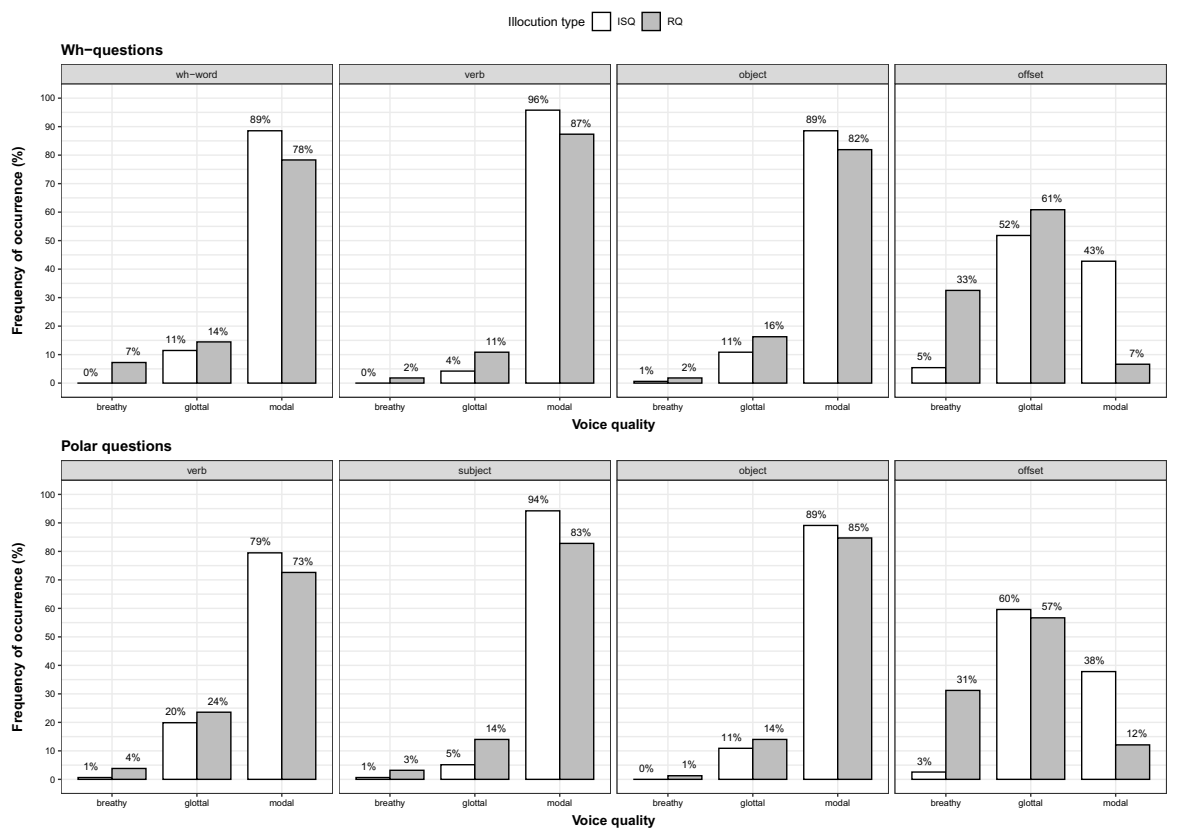

Figure 1. VQ at four positions in wh-questions (top) and polar questions (bottom).

significantly more often realized with glottal VQ than $w h$-questions $(\beta=0.91$, $\left.S E=0.25, z=3.68, p<.001, p_{a d j}<.01\right)$. For modal VQ, there were main effects of both illocution type and question type. RQs were less often realized with initial modal VQ than ISQs $\left(\beta=-0.74, S E=0.23, z=-3.21, p=p_{a d j}<.01\right)$, and polar questions were less often realized with modal VQ than wh-questions $(\beta=-0.66$, $\left.S E=0.23, z=-2.81, p<.001, p_{a d j}<.05\right)$.

In second position (einhver in polar, verb in $w$ h-questions), RQs were realized with glottal VQ more often than ISQs $\left(\beta=1.1, S E=0.35, z=3.11, p=p_{a d j}<.01\right)$; there was no main effect of question type $\left(p>.05, p_{a d j}<.07\right)$. For modal VQ, there was a main effect of illocution type; across question types, ISQs were produced with modal VQ more often than RQs $\left(\beta=-1.09, S E=0.35, z=3.1, p=p_{a d j}<.01\right)$.

In third position (first syllable of object noun), there were no main effects of illocution type on glottalized VQ $\left(p=p_{a d j}>.1\right)$ or modal VQ $\left(p=p_{a d j}>.1\right)$. Overall, there was a higher occurrence of glottalized voice in RQs as compared to ISQs, and more ISQs than RQs were realized with modal VQ.

Finally, at the offset of the utterance, all three VQs occurred with frequency high enough to allow for statistical analysis. For breathy VQ, no interaction between illocution type and question type was observed $\left(p=p_{a d j}>.7\right)$ and there was no effect of question type $\left(p=p_{a d j}<.3\right)$. There was a main effect of illocution type: RQs showed significantly more occurrences of breathiness than ISQs $(\beta=1.88, S E=0.22$, $\left.z=8.65, p=p_{a d j}<.001\right)$. There was an interaction between illocution type and question type for modal VQ $\left(\beta=0.63, S E=0.22, z=2.9, p<.01, p_{\text {adj }}<.05\right)$. In polar questions, ISQs were more often realized with final glottalized VQ than 


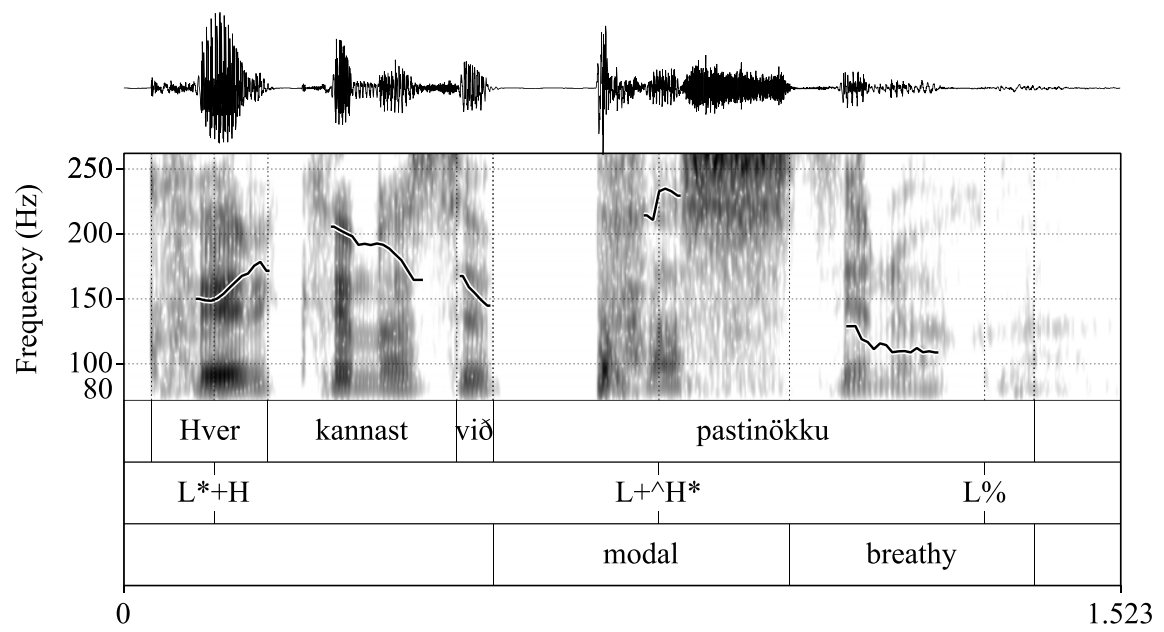

Time (s)

Figure 2. Wh-RQ (Hver kannast við pastinökku 'Who knows parsnips?') with sentence-final breathy VQ.

RQs. Conversely, glottalized VQ was more frequent in $w h$-RQs than in $w h$-ISQs. There were no main effects $(p>.3)$. An interaction between illocution type and question type was also observed for modal VQ $(\beta=1.09, S E=0.29, z=3.8$, $\left.p=p_{a d j}<.001\right)$, suggesting a stronger difference for modal VQ in $w h$-questions than in polar questions in this position. A main effect of illocution type was observed such that RQs were significantly less often realized with modal VQ than ISQs $\left(\beta=-3.04, S E=0.13, z=-5.6, p=p_{a d j}<.001\right)$.

Note that two non-modal VQs may occur on different syllables of the object noun. Specifically, of all items with breathy VQ at the offset, $17.2 \%$ were glottalized on the first syllable of the noun (78.5\% modal, $4.3 \%$ breathy), with generally more glottal VQ in RQs (see above).

Figures 2 and 3 illustrate sentence-final breathy VQ and sentence-final glottalized VQ, respectively, in wh-RQs. Figure 4 shows sentence-final modal VQ in a $w h$-ISQ.

\subsection{Speaking rate/duration}

The results for speaking rate are plotted in Figure 5. There was no significant interaction between illocution type and question type $\left(p=p_{a d j}>.3\right)$, but main effects of illocution type and question type were observed. RQs had slower speaking rate (significantly fewer syllables per second) than ISQs (polar: 5.2 (RQs) vs. 6.4 (ISQs) syllables per second; $w h: 4.3$ (RQs) vs. 5.7 (ISQs); $\beta=-1.24$, $\left.S E=0.1, t=-11.92, p=p_{a d j}<.0001\right)$. Wh-questions were produced with a significantly slower speaking rate than polar questions $(\beta=-0.74, S E=0.08, t=-9.29$, $\left.p=p_{a d j}<.0001\right)$.

The results for global duration, plotted in Figure 6, show an interaction between illocution type and question type $\left(\beta=53.63, S E=21.57, t=2.48, p=p_{\text {adj }}<.05\right)$, 


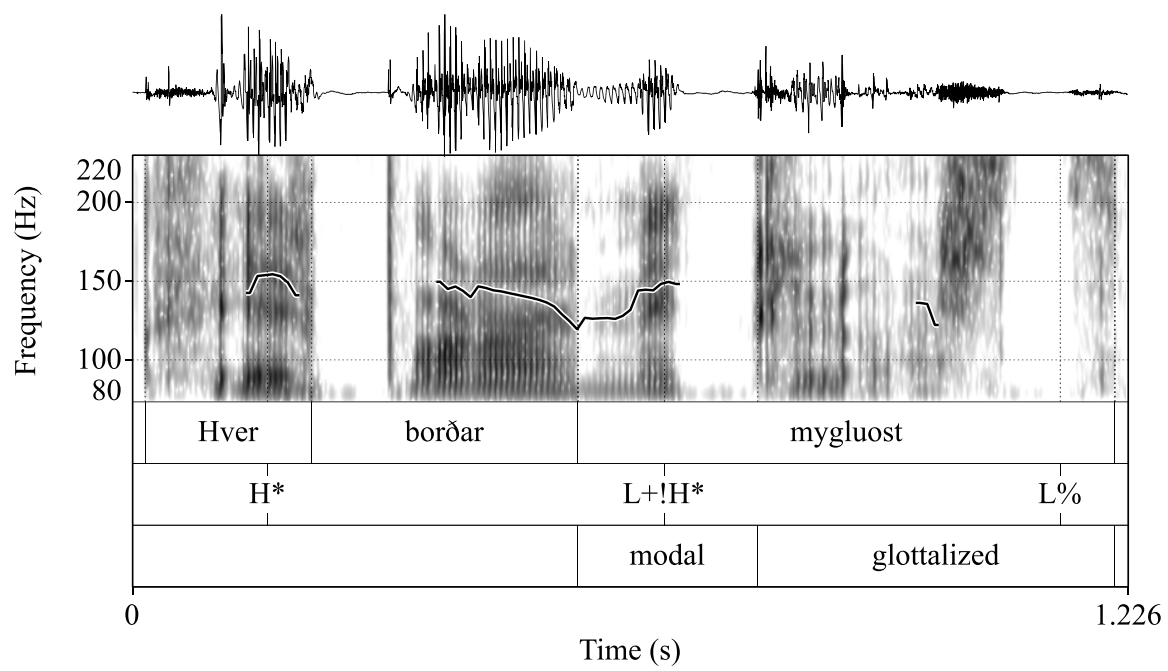

Figure 3. Wh-RQ (Hver borðar mygluost 'Who eats mould cheese?') with sentence-final glottalized VQ.

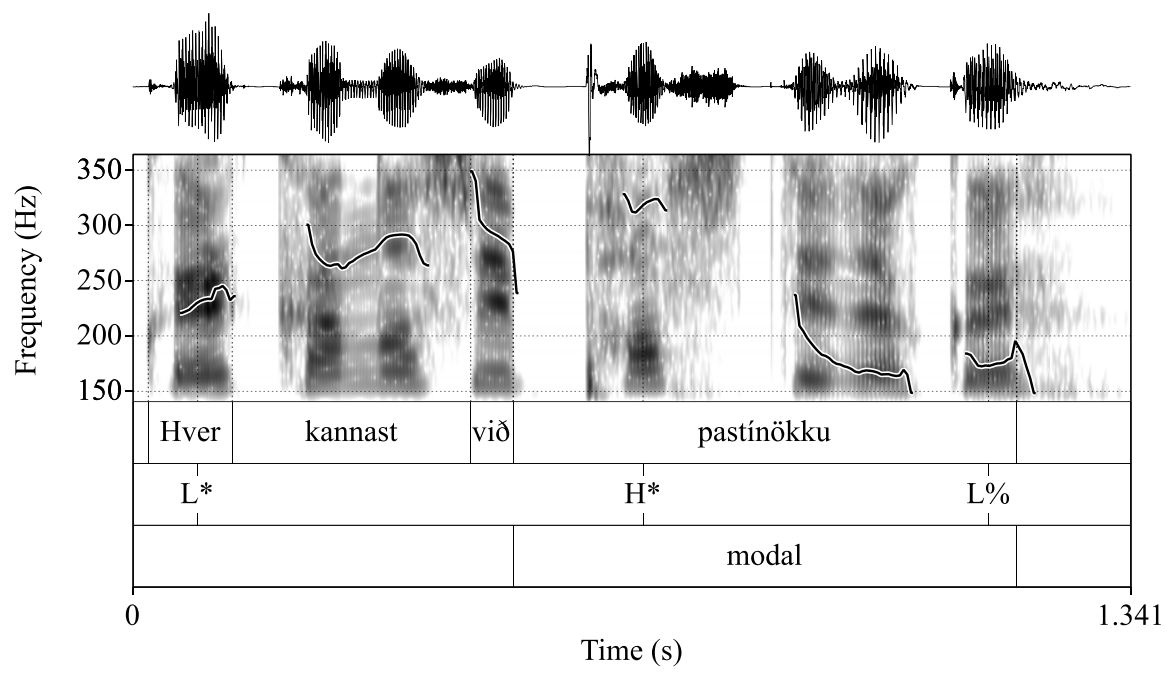

Figure 4. Wh-ISQ (Hver kannast við pastinökku 'Who knows parsnips?') with sentence-final modal VQ.

suggesting stronger durational differences in wh- than in polar questions. A main effect of illocution type was observed across question types: RQs have significantly longer average durations than ISQs (polar: $1325.2 \mathrm{~ms}$ (RQs) vs. $1076.9 \mathrm{~ms}$ (ISQs); $w h: 1315.8 \mathrm{~ms}$ (RQs) vs. $1029.8 \mathrm{~ms}$ (ISQs); $\beta=267.93, S E=24.27, t=11.04$, $\left.p=p_{a d j}<.001\right)$. Wh-questions have slightly shorter duration than polar questions, but this difference is not significant $\left(p=.0614, p_{a d j}>.1\right)$. 


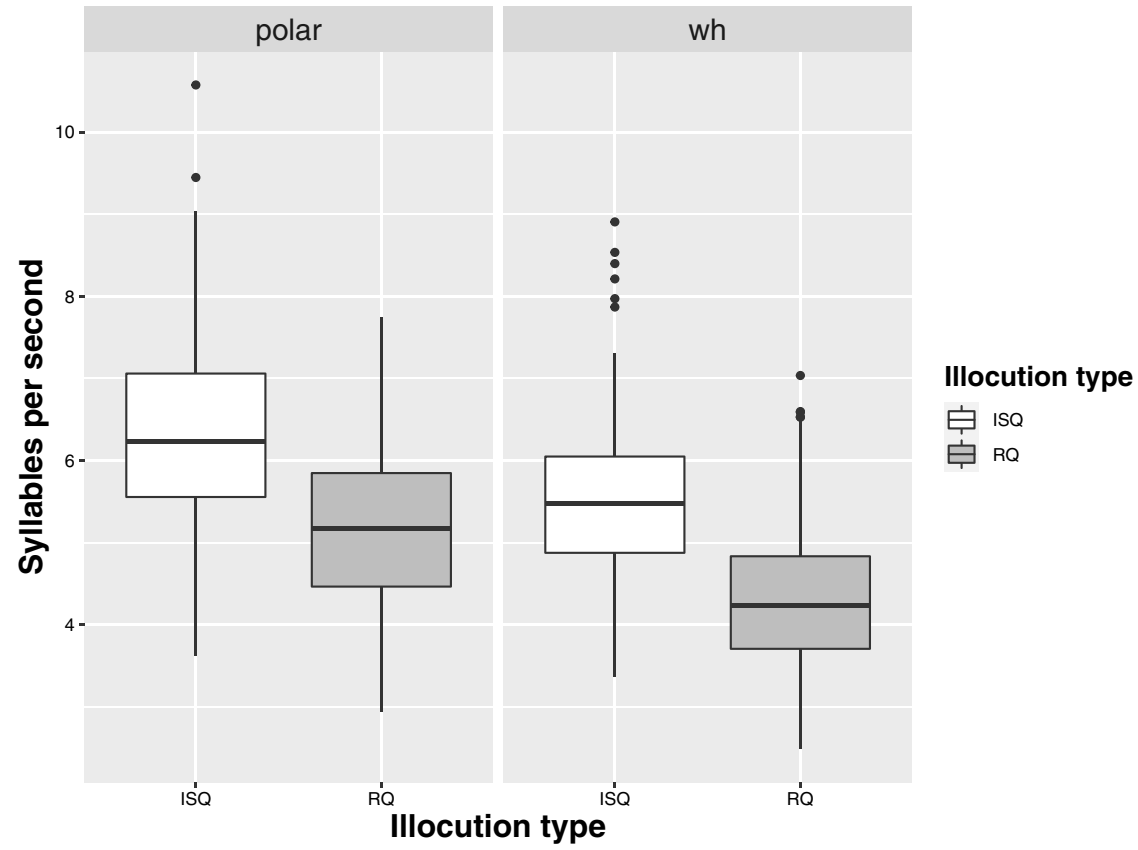

Figure 5. Average speaking rate of RQs and ISQs in polar and wh-questions.

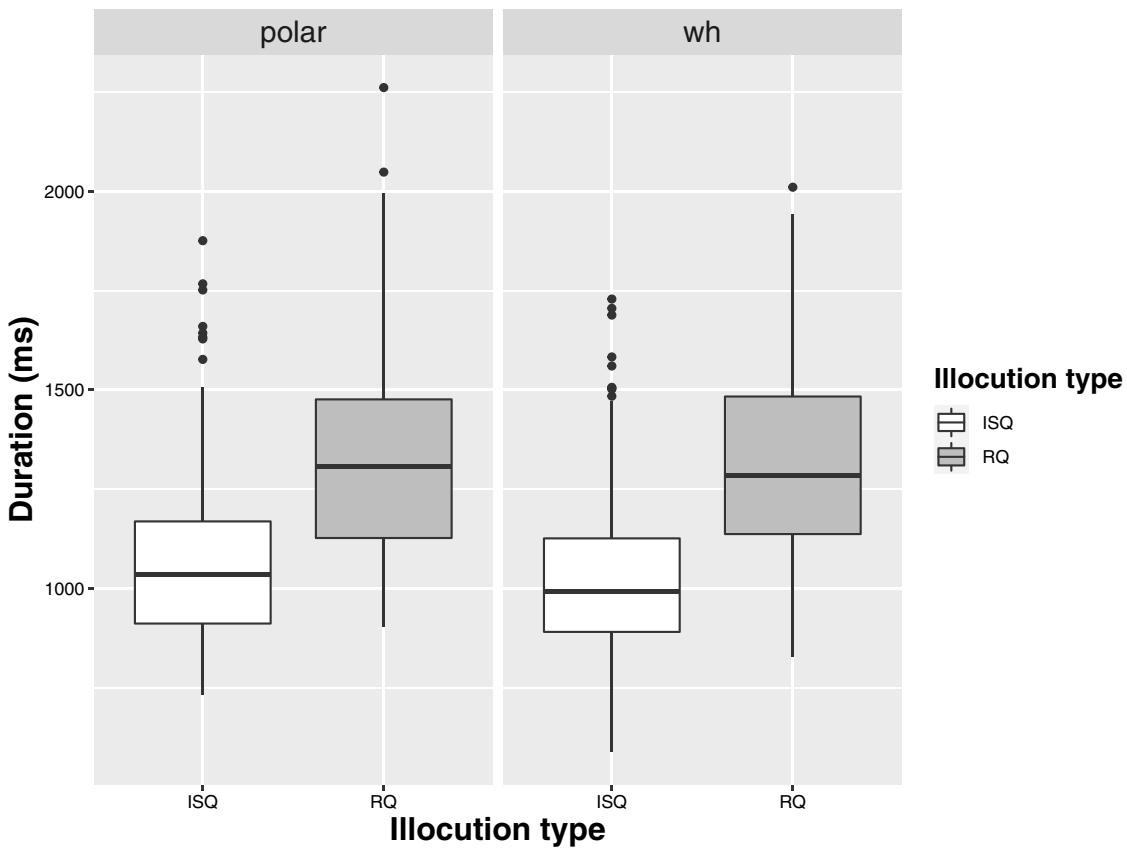

Figure 6. Sentence duration (ms) of RQs and ISQs across question types. 


\section{Discussion}

The analysis reveals that RQs in Icelandic differ from ISQs in terms of VQ and speaking rate/duration. First, RQs are generally longer than ISQs, as well as realized with a slower speaking rate. This is in line with results for other languages (see Section 1 above), suggesting that temporal cues are used cross-linguistically to distinguish between RQs and ISQs in prosody. A reviewer suggests that RQs may come with paralinguistic attitudes such as anger, exasperation or scornfulness, of which the slower speaking rate would be a correlate, rather than of the rhetorical meaning. Neitsch (2018) compared RQs with and without strong speaker attitudes, showing that both types of RQs exhibit the same prosodic parameters, among them longer durations than ISQs, with stronger magnitude for RQs with strong speaker attitudes.

Second, like German and English, Icelandic makes use of breathy VQ in the production of RQs. However, there are also differences between the languages. In German, both polar and wh-RQs often have breathy voice in sentence-initial position (Braun et al. 2019). In English, only wh-questions show differences in VQ (breathy voice in initial position in wh-RQs; Dehé \& Braun 2020b). In Icelandic RQs, initial breathiness is rare. Instead, breathy voice mainly occurs in utterance-final position. We interpret this positional difference between German and English on the one hand and Icelandic on the other as an interaction between VQ and intonation. In German and English, boundary tones distinguish between utterance types (e.g. questions vs. statements; see von Essen 1964, Brinkmann \& Benzm)̂ller 1999 for German; Bartels 1999 for English). This is not the case in Icelandic, where the default boundary tone for all utterance types is $\mathrm{L} \%$, including both polar and wh-questions (Árnason 2005, 2011; Dehé \& Braun 2020a). Moreover, in German and English, polar RQs are distinguished from polar ISQs by means of boundary tones (high rising boundary tone in ISQs vs. high plateau in RQs; Braun et al. 2019 for German, Dehé \& Braun 2020b for English), which is not the case in Icelandic (Dehé \& Braun 2020a). In German, boundary tones also distinguish between $w h$-ISQs and $w h$-RQs (mandatory fall in $w h$-RQs, high number of rising movements in wh-ISQs, Braun et al. 2019). While this is not the case in English (L\% in both RQs and ISQs), constituent duration steps in, with longer duration of the final object in wh-RQs than ISQs (Dehé \& Braun 2020b). In Icelandic, despite the general availability of the high boundary tone $(\mathrm{H} \%)$ to mark special aspects of meaning (Árnason 2005, 2011), this cue is not used for the expression of rhetorical meaning. Both ISQs and RQs end in L\% (Dehé \& Braun 2020a). It is therefore conceivable that Icelandic speakers exploit the manipulation of VQ in final position as a compensation strategy. As an apparent general boundary marker, used in both ISQs and RQs to a considerable extent, glottalized voice is not the preferred option to signal rhetorical meaning. Instead, breathy voice marks the offset of RQs. Breathiness has also been found at the terminus of polar questions in African languages of the Gur family. Interestingly, polar questions in those languages typically end in a fall, too (Rialland 2009). This further supports the assumption that final VQ may replace boundary tones as a cue to illocution type. Future research will show whether Icelandic also makes use of VQ as a cue to pragmatic meaning in other utterance types (e.g. exclamatives, see Wochner 2021 for 
German) or in statements with specific pragmatic connotations (e.g. emphasis, see Niebuhr et al. 2010, or obviousness, see Wochner 2021). Generally speaking, Icelandic fits in with previous studies showing that non-modal VQ is crosslinguistically used as a cue to rhetorical meaning in questions, although the particular ways in which non-modal VQ is used is language-specific.

Acknowledgements. We thank Bettina Braun and Katharina Zahner-Ritter for statistical advice, Johanna Schnell and Gloria Sigwarth for data annotations, and three reviewers for NJL for their comments. The research was funded by the DFG, grant numbers DE 876/3-1 and DE 876/3-2.

\section{Note}

1 Previous research comparing VQ in German RQs and ISQs showed that given the variability of the experimental material, a perceptual analysis was more robust than acoustic measures (Braun et al. 2019). Data from 11 female speakers of the current study was also classified in a random forest model (model included measures of HNR, H1-A2, H1-A3, $1^{*}-\mathrm{A}^{*}$, cepstral-peak prominence, glottal to noise excitation ratio, and b1 and b2 measurements); the accuracy of the model was $78.6 \%$ overall (Braun et al. 2021).

\section{References}

Agresti, Alan. 2002. Categorical Data Analysis. New York: Wiley.

Árnason, Kristján. 2005. Hljóð. Handbók um hljóðfræeði og hljóðkerfisfræeði [Sound: A handbook of phonetics and phonology]. Reykjavík: Almenna bókafélagið.

Árnason, Kristján. 2011. The Phonology of Icelandic and Faroese. Oxford: Oxford University Press.

Asu, Eva Liina, Heete Sahkai \& Pärtel Lippus. 2020. The prosody of rhetorical and information-seeking questions in Estonian: Preliminary results. Proceedings of Speech Prosody 2020, Tokyo, Japan, 381-384. doi: 10.21437/SpeechProsody.2020-78.

Bartels, Christina. 1999. The Intonation of English Statements and Questions: A Compositional Approach. New York \& London: Garland.

Bates, Douglas, Reinhold Kliegl, Shravan Vasishth \& Harald Baayen. 2015. Parsimonious mixed models. arXiv:1506.04967.

Benjamini, Yoav \& Yosef Hochberg. 1995. Controlling the false discovery rate: A practical and powerful approach to multiple testing. Journal of the Royal Statistical Society, Series B 57, 289-300.

Beyssade, Claire \& Elisabeth Delais-Roussarie. To appear. Prosodic study of French rhetorical questions. Linguistic Vanguard.

Boersma, Paul \& David Weenink. 2018. Praat: Doing phonetics by the computer. http://www.praat.org/.

Braun, Bettina, Nicole Dehé, Marieke Einfeldt, Daniela Wochner \& Katharina Zahner-Ritter. 2021. Testing acoustic voice quality classification across languages and speech styles. Proceedings of Interspeech 2021, 30 Aug - 3 Sep 2021, Brno, Czechia, 3920-3924. doi: 10.21437/Interspeech.2021-315.

Braun, Bettina, Nicole Dehé, Jana Neitsch, Daniela Wochner \& Katharina Zahner. 2019. The prosody of rhetorical and information-seeking questions in German. Language and Speech 62(4), 779-807.

Brinckmann, Carmen \& Ralf Benzmîller. 1999. The relationship between utterance type and F0 contour in German. Proceedings of the 6th European Conference on Speech Communication and Technology (Eurospeech 1999), Budapest, 21-24.

Cohen, Jacob. 1960. A coefficient of agreement for nominal scales. Educational and Psychological Measurement 20, 37-46.

Dehé, Nicole \& Bettina Braun. 2020a. The intonation of information-seeking and rhetorical questions in Icelandic. Journal of Germanic Linguistics 32(1),1-42.

Dehé, Nicole \& Bettina Braun. 2020b. The prosody of rhetorical questions in English. English Language \& Linguistics 24(4), 607-635.

Dehé, Nicole, Bettina Braun, Marieke Einfeldt, Daniela Wochner \& Katharina Zahner. 2022. The prosody of rhetorical questions: A cross-linguistic view. Linguistische Berichte 269, 3-42. 
Dehé, Nicole, Bettina Braun \& Daniela Wochner. 2018. The prosody of rhetorical vs. information-seeking questions in Icelandic. Proceedings of Speech Prosody 9 (2018), 13-16 June 2018, Poznań, Poland, 403-407. doi: 10.21437/SpeechProsody.2018-82.

Han, Chung-hye. 2002. Interpreting interrogatives as rhetorical questions. Lingua 112, 201-229.

Landis, J. Richard \& Gary G. Koch. 1977. An application of hierarchical kappa-type statistics in the assessment of majority agreement among multiple observers. Biometrics 33(2), 363-374.

Laver, John. 1980. The Phonetic Description of Voice Quality. Cambridge: Cambridge University Press.

Lo, Roger Yu-Hsiang, Angela Kiss \& Maxime Tulling. 2019. The prosodic properties of the Cantonese sentence-final particles aal and aa3 in rhetorical wh-questions. In Sasha Calhoun, Paola Escudero, Marija Tabain \& Paul Warren (eds.), Proceedings of the 19th International Congress of Phonetic Sciences (ICPhS XIX), Melbourne, Australia, 502-506. Australasian Speech Science and Technology Association.

Matuschek, Hannes, Reinhold Kliegl, Shravan Vasishth, Harald Baayen \& Douglas Bates. 2017. Balancing Type I error and power in linear mixed models. Journal of Memory and Language 94, 305-315.

Miura, Ichiro \& Noriyo Hara. 1995. Production and perception of rhetorical questions in Osaka Japanese. Journal of Phonetics 23, 291-303.

Neitsch, Jana. 2018. The prosody of rhetorical questions in consideration of context. Poster presented at the workshop Meaning in Non-canonical Questions, University of Konstanz, Germany.

Niebuhr, Oliver, Julia Bergherr, Susanne Huth, Cassandra Lill \& Jessica Neuschulz. 2010. Intonationsfragen hinterfragt. Die Vielschichtigkeit der prosodischen Unterschiede zwischen Aussageund Fragesätzen mit deklarativer Syntax [The complexity of the prosodic differences between statements and questions with declarative syntax]. Zeitschrift für Dialektologie und Linguistik 77, 304-346.

Rialland, Annie. 2009. The African lax question prosody: Its realization and geographical distribution. Lingua 119, 928-949.

R Core Team. 2013. R: A language and environment for statistical computing. Vienna: R Foundation for Statistical Computing. http://www.R-project.org/.

Sorianello, Patrizia. 2018. Tra prosodia e pragmatica: il caso delle domande retoriche [Between prosody and pragmatics: The case of rhetorical questions]. Studia e Saggi Linguistici 2, 39-71.

Sorianello, Patrizia. 2019. 'A che serve saperlo?' Funzioni pragmatiche e variazioni intonative della domanda retorica ['What's the use of knowing this?': Pragmatic functions and intonational variations of rhetorical questions]. In Elena Nuzzo \& Ineke Vedder (eds.), Studi AItLA 9: Lingua in contesto. La prospettiva pragmatica [Language in context: The pragmatic prospective], 89-108. Milan: Officinaventuno.

Van Heuven, Vincent J. \& Ellen van Zanten. 2005. Speech rate as a secondary prosodic characteristic of polarity questions in three languages. Speech Communication 47, 87-99.

von Essen, Otto. 1964. Grundzüge der Hochdeutschen Satzintonation [Main features of High German sentence intonation]. Ratingen: Henn.

Wochner, Daniela. 2021. Prosody Meets Pragmatics: A Comparison of Rhetorical Questions, Information-seeking Questions, Exclamatives, and Assertions. Ph.D. dissertation, University of Konstanz.

Zahner, Katharina, Yiya Chen, Nicole Dehé \& Bettina Braun. 2021. Prosodic differences between rhetorical and information-seeking questions in Standard Chinese. Ms., University of Konstanz \& University of Leiden.

Cite this article: Dehé $\mathrm{N}$ and Wochner D. Voice quality and speaking rate in Icelandic rhetorical questions. Nordic Journal of Linguistics. https://doi.org/10.1017/S0332586522000014 